\title{
The biosphere as a driving force in the global carbon cycle*
}

\section{J. Goudriaan}

Department of Theoretical Production Ecology, Wageningen Agricultural University, P.O. Box 430, 6700 AK Wageningen, Netherlands

Received 2 February 1987; accepted 26 February 1987

Key words: rising atmospheric $\mathrm{CO}_{2}$, climatic change, $\mathrm{CO}_{2}$ assimilation, global carbon cycle, biosphere

\begin{abstract}
Atmospheric $\mathrm{CO}_{2}$ and growth of green plants affect each other vice versa. Not only is atmospheric $\mathrm{CO}_{2}$ suboptimal for plant growth, the amount of carbon tied up in biomass is of the same order of magnitude as the amount in atmospheric $\mathrm{CO}_{2}$. The biosphere maintains strong exchange fluxes of carbon by assimilation and respiration, both on land and in the sea. Cessation of either terrestrial or marine biospheric carbon fixation would lead to doubling of atmospheric $\mathrm{CO}_{2}$ within a few hundred years.

Past fluctuations of atmospheric $\mathrm{CO}_{2}$ have probably been strongly amplified or even caused by the biosphere, in interaction with the climatic greenhouse effect of atmospheric $\mathrm{CO}_{2}$. Depletion of atmospheric $\mathrm{CO}_{2}$ by the end of the Tertiary was probably a major factor in both the evolution of $\mathrm{C}_{4}$ plants and the onset of the glacial periods. Geologically, the man-made enrichment of the atmosphere with $\mathrm{CO}_{2}$ has hardly started, and it is expected to lead to climatic and biospheric changes comparable in size to those leading to transitions between geological periods in the remote past.
\end{abstract}

\section{Introduction}

Atmospheric $\mathrm{CO}_{2}$ has a central position in the global carbon cycle, because exchange fluxes between the world's major carbon reservoirs are mainly in the form of $\mathrm{CO}_{2}$. Industrial development, and the corresponding fossil fuel consumption, enhance the natural carbon cycle by the injection of considerable masses of $\mathrm{CO}_{2}$ into the atmosphere. Since the beginning of the industrial era about 200 years ago, the atmospheric $\mathrm{CO}_{2}$ content has risen from about $280 \mathrm{~cm}^{3} / \mathrm{m}^{3}$ via $325 \mathrm{~cm}^{3} / \mathrm{m}^{3}$ in 1970 to $345 \mathrm{~cm}^{3} / \mathrm{m}^{3}$ now (Trabalka, 1985). The $\mathrm{CO}_{2}$ released into the atmosphere is not in-

* Paper presented at the symposium 'The Global Carbon Cycle', held 24 October 1986 on the occasion of the retirement of Prof. Dr Ir J. F. G. M. Wintermans from the University of Nijmegen. 


\section{J. GOUDRIAAN}

ert, but is redistributed over the other carbon reservoirs. The most important absorber of atmospheric $\mathrm{CO}_{2}$ is the ocean. It reduces the annual increase of atmospheric $\mathrm{CO}_{2}$ to about $60 \%$ of the amount annually released by combustion of fossil fuels (Bolin et al., 1979). The major fluxes in the natural carbon cycle are more than ten times as large as the man-made injection of $\mathrm{CO}_{2}$ by burning of fossil fuel. The dynamic equilibrium between the natural fluxes is gradually shifted by this steady man-made addition of $\mathrm{CO}_{2}$ to the atmosphere.

Potential climatic effects of atmospheric $\mathrm{CO}_{2}$ are a reason for concern, also on a governmental level in the Netherlands (Gezondheidsraad, 1983; 1986). The expected global warming, known as the greenhouse effect, might lead to an uncomfortable rise of sea level, and to changes of the vegetation zones. In this paper the role of the biosphere as an active driving force in the global carbon cycle will be stressed. On the other hand biospheric activity also depends directly on the atmospheric $\mathrm{CO}_{2}$ content (Gifford, 1982; Anon., 1985).

\section{$\mathrm{CO}_{2}$ as a climatic factor}

The role of $\mathrm{CO}_{2}$ in the energy balance of planet Earth can be loosely compared to the action that an envelope of glass would have: it transmits solar radiation to the surface of the earth, but it intercepts the black-body radiation, emitted by the soil surface. Only a part of this radiative energy flux is re-emitted into space, whereas the downward component of this re-emission causes a higher incoming radiative energy level at the earth surface than the solar flux alone. Thanks to this atmospheric action the global average surface temperature is about $15^{\circ} \mathrm{C}$ instead of $-18^{\circ} \mathrm{C}$ (Dickinson, 1982). Because of the analogy this climatic action of $\mathrm{CO}_{2}$ is called the 'greenhouse' effect. $\mathrm{CO}_{2}$ is not the only 'greenhouse' gas, in fact water vapour is the most important one, and a number of other gases such as $\mathrm{O}_{3}, \mathrm{NO}_{2}$, $\mathrm{NH}_{3}$, and CFKs (freon-like gases) appear to become increasingly important (Chamberlain et al., 1982). By addition of $\mathrm{CO}_{2}$ to the atmosphere the natural 'greenhouse' effect is enhanced, and the temperature at the earth surface can be expected to increase.

The relation between $\mathrm{CO}_{2}$ addition and expected temperature increase is a subject of extensive study, mainly by means of climatic modelling (Washington \& Parkinson, 1986). Predictions are considerably complicated by the strong greenhouse effect of water vapour, which itself is a climatic factor that will be altered. Increasing air temperature will lead to more evaporation (and consequently precipitation) so that the total water vapour content of the atmosphere is also expected to increase, and the single $\mathrm{CO}_{2}$ effect will be enhanced. This water vapour feedback factor is estimated to be as large as about 2 or 3 . Increased cloud formation may cause some negative feedback.

The best modelling results presently available indicate an average global warming of about 1.5 to $4.5^{\circ} \mathrm{C}$ (Schlesinger \& Mitchell, 1985). As the temperature increase will be the largest (up to $10^{\circ} \mathrm{C}$ ) in the cold and dark polar winters, and the smallest in the tropics, the temperature gradients across the globe will be reduced. 
The hydrological cycle (evaporation/precipitation) will be intensified by about $10 \%$. These rainfall effects, however, may be highly regional.

\section{$\mathrm{CO}_{2}$ as a biotic factor}

The importance of air as a carrier of raw material for plant growth has been known since the end of the 18 th Century, and was discovered by people like Van IngenHousz, Priestly and Senebier. Much earlier, Lucretius preluded on the idea of elemental geophysical cycles when he wrote that the sky, the sea, the earth, the sun, the rivers, the fruits, the forests and living beings all consist of the same elements, albeit interconnected in different ways (Lucretius, $60 \mathrm{BC}$ ). We know now that biomass mainly exists of carbon and water, enriched with a small fraction of nutrient elements. Almost all of the carbon in the plant is taken up as $\mathrm{CO}_{2}$ from the air. The weight fraction of carbon in dry weight of plant material is rather stable between 40 and $50 \%$, so that there must be a close connection between $\mathrm{CO}_{2}$ assimilation and dry weight gain. Plant physiological and agricultural research has shown the importance of environmental factors such as radiation level, water supply, nutrient supply and temperature for the processes of growth, photosynthesis and $\mathrm{CO}_{2}$ assimilation, but also of the concentration of ambient $\mathrm{CO}_{2}$ itself. In general the normal ambient $\mathrm{CO}_{2}$ concentration of about $300-330 \mathrm{~cm}^{3} / \mathrm{m}^{3}$ is suboptimal, and higher growth rates of green plants can be realized at a concentration of about $1000 \mathrm{~cm}^{3} / \mathrm{m}^{3}$ (Lemon, 1984; Strain \& Cure, 1985). At that level the favourable $\mathrm{CO}_{2}$ effect on growth is practically saturated, and the growth rate may be more than 1.5 times as high as under normal conditions. Small increments of atmospheric $\mathrm{CO}_{2}$ lead to increments in biomass production that are about $1 / 2$ to $3 / 4$ as large, both expressed as relative changes. Indeed, about $1 / 10$ to $1 / 6$ of the annual increment of world food production is freely obtained as an unrequested side-effect of increasing atmospheric $\mathrm{CO}_{2}$. The acceleration of growth is not as strong under unsufficient nutrient supply (Goudriaan \& de Ruiter, 1983) or may be even absent. Water shortage, on the other hand, does not diminish the relative stimulation by higher $\mathrm{CO}_{2}$; on the contrary, it may even enhance it (Gifford, 1979). Also under low radiation levels a considerable positive $\mathrm{CO}_{2}$ effect remains. The generally favourable $\mathrm{CO}_{2}$ effect is well known in horticulture and has found wide-spread practical application (Enoch \& Kimball, 1986).

\section{Global reservoirs and fluxes of carbon (Fig. 1)}

Huge amounts of carbon lie tied up in carbonates in the earth crust, but these are only important on very long geological time scales. Much more interesting on the short time scale of decades is the reduced carbon, present as coal, oil and natural gas. Because of its tremendous energy content, it is burnt and relocated from the earth crust into the atmosphere at a rate of about $5 \times 10^{15} \mathrm{~g} \mathrm{C} \mathrm{a}^{-1}$. When this flux rate is compared to the total amount of carbon in the atmosphere, which is about $700 \mathrm{Gt}\left(1 \mathrm{Gt}=10^{15} \mathrm{~g}\right)$, it is clear that this rate is bound to have a large effect on a time scale of a hundred years or so. The reservoir of fossil carbon on the other hand is much larger, several thousands of gigatonnes $C$, and perhaps even much larger, 


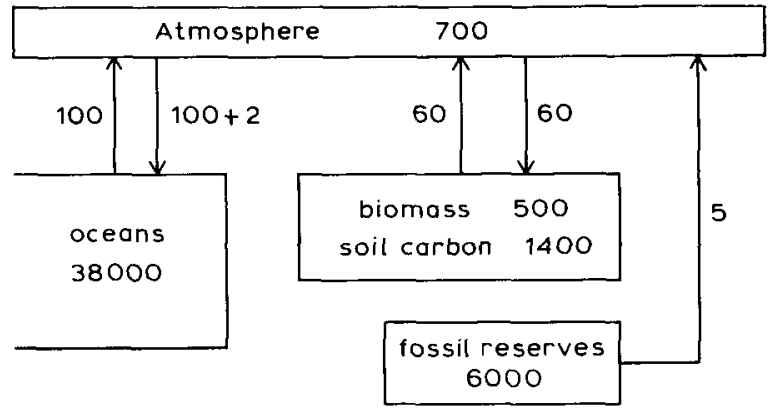

Fig. 1. Global reservoirs of carbon, active in exchange, expressed in $\mathrm{Gt}$ $\mathrm{C}$, and their exchange fluxes in $\mathrm{Gt}$ $\mathrm{a}^{-1}$. The atmosphere receives $5 \mathrm{Gt} \mathrm{C}$ annually from fossil fuel combustion. Because the present atmospheric carbon concentration is out of equilibrium with the ocean, the atmosphere looses $2 \mathrm{Gt} \mathrm{a}^{-1}$ more to the ocean than is returned.

dependent on the efficiency of exploration. Anyway, the reserves of fossil fuel are so large that long before they will be exhausted, a large effect of their burning can be expected on the atmospheric $\mathrm{CO}_{2}$ content.

The net rate of increase of atmospheric $\mathrm{CO}_{2}$ is at present only about $60 \%$ of the rate of fossil fuel combustion. The other $40 \%$ (about $2 \mathrm{Gt} \mathrm{C} \mathrm{a}^{-1}$ ) is absorbed by the oceans. The amount of carbon present in the ocean is huge, about $38000 \mathrm{Gt}$, but this figure is deceptive as a guideline for estimating the redistribution of $\mathrm{CO}_{2}$ between atmosphere and ocean. First, complete mixing through the deep sea takes time, several hundreds of years. And second, most of the ocean carbon is locked away beyond chemical equilibrium in the form of bicarbonate. The net effect of the carbon chemistry of sea water is that its relative change in carbon content is only one tenth of the relative change of partial pressure of $\mathrm{CO}_{2}$. This large chemical resistance increases even further with increasing $\mathrm{CO}_{2}$ uptake. Nevertheless, the ocean is large enough to potentially absorb as much as $85 \%$ of $\mathrm{CO}_{2}$ injected into the atmosphere. The difference with the present uptake of $40 \%$ is caused by the slow rate of mixing. Eventually the deep sea will take its share. Much of this knowledge on transport in oceans, but also in and between the other pools of carbon, has been obtained by isotope research (Mook, 1986).

The oceanic uptake that we see now is still mainly stored in the surface waters of the ocean. These upper hundred or so meters are internally well mixed, but isolated from the deep sea by thermal stratification. Only in the higher latitudes is the stratification broken, so that exchange occurs. There cooled water sinks down, carrying $\mathrm{CO}_{2}$ with it. The counter-flow of upwelling deep water is mainly found in the tropics. This slow circular mass flow of water causes a renewal of the deep sea water once every few hundreds of years on the average. When the upwelling cold water is warmed up in the tropics, $\mathrm{CO}_{2}$ is released, as much as $4 \mathrm{Gt} \mathrm{C} \mathrm{a}^{-1}$. Indeed, accurate measurements of atmospheric $\mathrm{CO}_{2}$ concentration show a persistent equatorial bulge (Gammon et al., 1985).

Almost all biospheric carbon is stored on land, as wood, in leaves, in litter, and also in dead organic matter in humus (Olson et al., 1985). Live biomass is estimated to be close to $600 \mathrm{Gt} \mathrm{C}$, and humus to about $700 \mathrm{Gt} \mathrm{C}$. There is a fairly gradual transition from humus to inert, and practically elemental, carbon in the soil, which is another $700 \mathrm{Gt} \mathrm{C}$. These three subreservoirs together are generally considered as 
biotic, and store $2000 \mathrm{Gt} \mathrm{C}$. The residence time of carbon in these reservoirs varies from less than a year for leaves, through some decades in wood and humus, to several centuries or more in the inert carbon in the soil (Kortleven, 1963).

\section{Changes of atmospheric $\mathrm{CO}_{2}$ over various time scales}

On all time scales $\mathrm{CO}_{2}$ is changing. Usually one is not aware of the sizeable diurnal changes of $\mathrm{CO}_{2}$ in the lower few meters of the atmospheric boundary layer near the ground. Due to noctural respiration of soil and plants, atmospheric $\mathrm{CO}_{2}$ reaches a maximum in the morning, and decreases again in the daytime when the photosynthetic uptake is in operation. Especially in still, inversion-like weather the early morning level of $\mathrm{CO}_{2}$ may reach more than twice the mean value. Soon after sunrise the inversion is usually broken, photosynthesis starts and $\mathrm{CO}_{2}$ very quickly returns to a value between 320 and $380 \mathrm{~cm}^{3} / \mathrm{m}^{3}$. During the period of major photosynthetic activity the vegetation is surrounded by air not differing more than $20 \mathrm{~cm}^{3} / \mathrm{m}^{3}$ from the atmospheric mean.

These strong diurnal fluctuations prevent precise geophysical measurements of average atmospheric $\mathrm{CO}_{2}$, and so these measurements are done on mountain tops far from local sources. In this way the diurnal cycle is avoided, and a clear annual cycle can be made visible. The famous measurement series from Mauna Loa, Hawaii, shows the annual cycle, superimposed on a decadal time trend caused by fossil fuel combustion (Keeling et al., 1982).

Like the diurnal cycle, also the annual cycle is of biospheric origin. Of course the annual cycle is spatially much more extended than the diurnal one and comprises the full atmospheric column, but it varies considerably with place on earth. Most notably the phases on the Northern and Southern hemisphere are opposite, which shows that the time scale of atmospheric mixing of the two hemispheres is at least one year. The seasonality is most outspoken above the continents in the temperate zones, and almost absent in the equatorial zone (Fig. 2). There are indications that the seasonal amplitude of the $\mathrm{CO}_{2}$ signal has been increasing over the last decade (Revelle \& Kohlmaier, 1986). Several mechanisms may be responsible for this increase, such as an increasing biospheric activity per se, but also a growing time interval between periods of net growth and of net decay. As yet there is no conclusive evidence whether the increasing amplitude has anything to do with the increasing background level of $\mathrm{CO}_{2}$ itself.

In our own measurements in Wageningen the decadal increase of atmospheric $\mathrm{CO}_{2}$ is also clearly visible in records since 1970 of measurements of photosynthesis outdoors, done at CABO (Louwerse, pers. comm.).

The Mauna Loa series goes back to the 1950s. Earlier $\mathrm{CO}_{2}$ data are available from air bubbles, enclosed in polar ice (Neftel et al., 1985). These records show that the $\mathrm{CO}_{2}$ concentration has been gradually rising from about $280 \mathrm{~cm}^{3} / \mathrm{m}^{3}$ in 1800 . Probably this level is representative for the entire pre-industrial historic period.

Earlier back, during the glacial periods all time, minimum records of about 200 $\mathrm{cm}^{3} / \mathrm{m}^{3}$ were reached, as shown by the same ice core technique applied in the Antarctic ice cap (Neftel et al., 1982). During the interglacials the $\mathrm{CO}_{2}$ concentration 


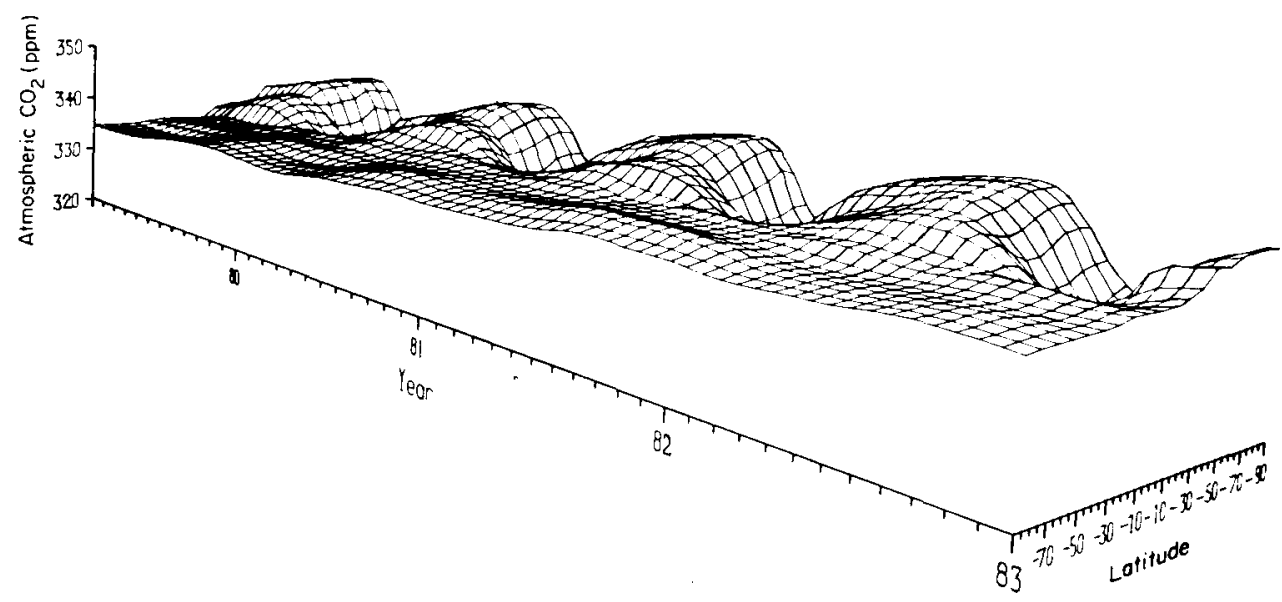

Fig. 2. Annual cycling of atmospheric $\mathrm{CO}_{2}$ is strongly dependent on latitude. Data from 15 sea-level sites (Harris \& Bodhaine, 1983 cited by Gammon et al., 1985). The strong seasonality on the northern hernisphere is due to the large amount of terrestrial vegetation there.

returned to close to $300 \mathrm{~cm}^{3} / \mathrm{m}^{3}$ with a transition period of only a few hundred years. A close synchrony existed between low temperatures and low $\mathrm{CO}_{2}$ levels, but the temperature drop was much stronger than expected from the $\mathrm{CO}_{2}$ drop alone. Therefore other factors, such as increased reflection of solar radiation by the vast ice cover, must have amplified the coupling. Also changes in biospheric activity in the oceans are likely to have been decisive for the flip-flop-like oscillations.

Ever since life began, atmospheric $\mathrm{CO}_{2}$ has been steadily decreasing until the glacial periods. Fossil coal reserves are witnesses of lush plant growth in the remote past, stimulated by high atmospheric $\mathrm{CO}_{2}$, that probably lay in the order of percents. In the Cambrium period solar luminosity was about $30 \%$ lower than nowadays, and so the continuous draw-down of atmospheric $\mathrm{CO}_{2}$ since then by the activity of the biosphere can be viewed as a compensation for the increasingly larger radiation load of the sun. This fortuitous maintenance of life-friendly conditions on our planet by life itself during millions of years has prompted the formulation of a hypothesis of goddess Gaia, who takes well care of herself (Lovelock, 1979). Whether the expected man-made changes of atmospheric $\mathrm{CO}_{2}$ (Fig. 3) are part of her strategy has not been revealed yet, but it is certain that they are of geological importance.

By the end of the Tertiary, $\mathrm{CO}_{2}$ was so far depleted that life must have become quite harsh for terrestrial plants. Large stomatal opening was necessary for $\mathrm{CO}_{2}$ uptake and caused a relatively high transpirational water loss. Frequent drought was more likely, and it is precisely under such conditions that the water-efficient $\mathrm{C}_{4}$ mechanism gives a large advantage over the regular $\mathrm{C}_{3}$ mechanism. The low $\mathrm{CO}_{2}$ level may have been a dominant factor in the evolution of the $\mathrm{C}_{4}$ species. Indeed, the oldest fossil records of $\mathrm{C}_{4}$ plants date from the Pliocene, which just preceded the glacial periods (Nambudiri et al., 1978). 


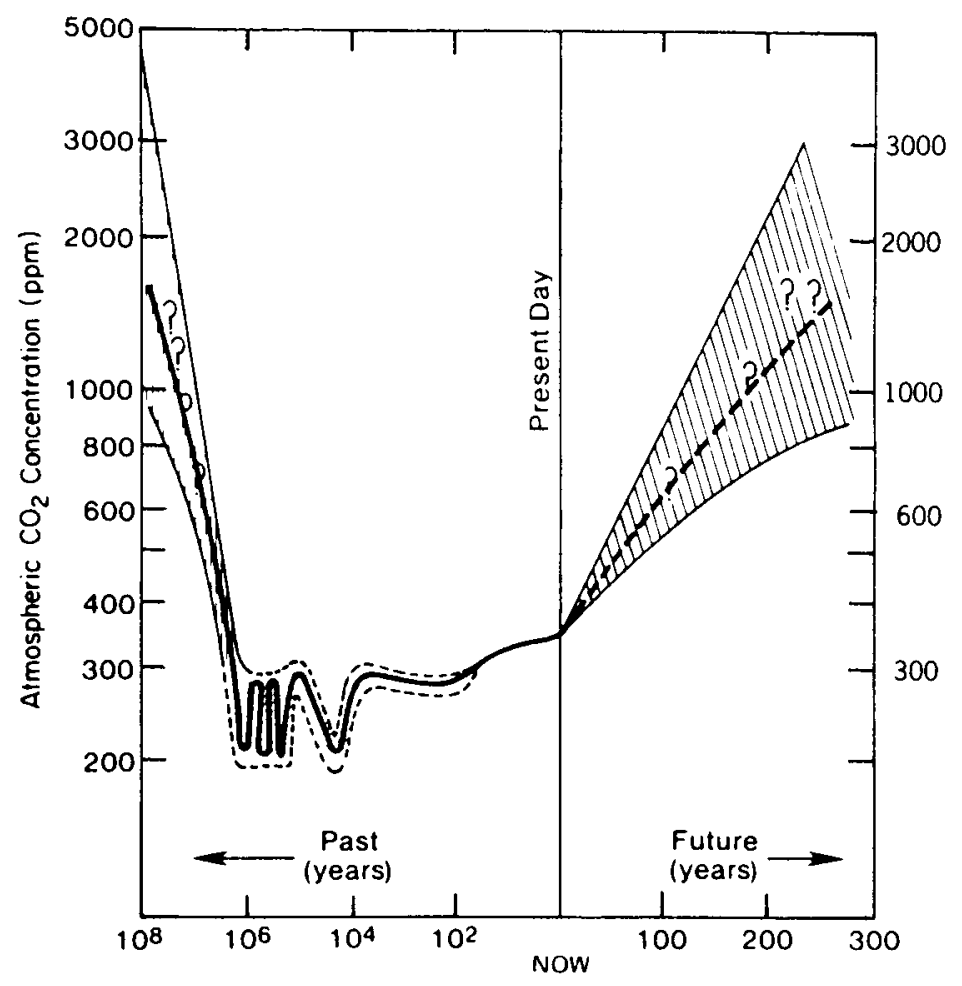

Fig. 3. Time course of atmospheric $\mathrm{CO}_{2}$ in history and expected in future. Hatching indicates level of uncertainty. Note the logarithmic time scale for the historic data.

\section{The biospheric pumps}

The reservoir of biospheric carbon on land is maintained by the equilibrium between photosynthesis and decay. With a global net annual $\mathrm{C}$ fixation estimated as $60 \mathrm{Gt}$ and a biospheric carbon pool of $2000 \mathrm{Gt}$ in total, the average life time of carbon in a simple one-box model would be 33 years. In a slightly more complicated model, a parallel-serial circuitry of components is visualized (Fig. 4) with various life times. For humus and inert carbon, this model structure can be derived from the work of Kortleven(1963), who showed that the response of humus level to litter input is of a first order character. For live biomass, this structure is founded on the work of van de Sande Bakhuyzen (1937). A compartmentalized model can much better represent the dynamics of changes than a one-box model. Such changes may be induced by human activities such as deforestation, and slash and burning agriculture. The recognition of different pools with widely different residence times helps to understand the twofold consequence of burning: it not only immediately releases $\mathrm{CO}_{2}$ into the atmosphere, but it also fixes a small fraction of the carbon of the mate- 


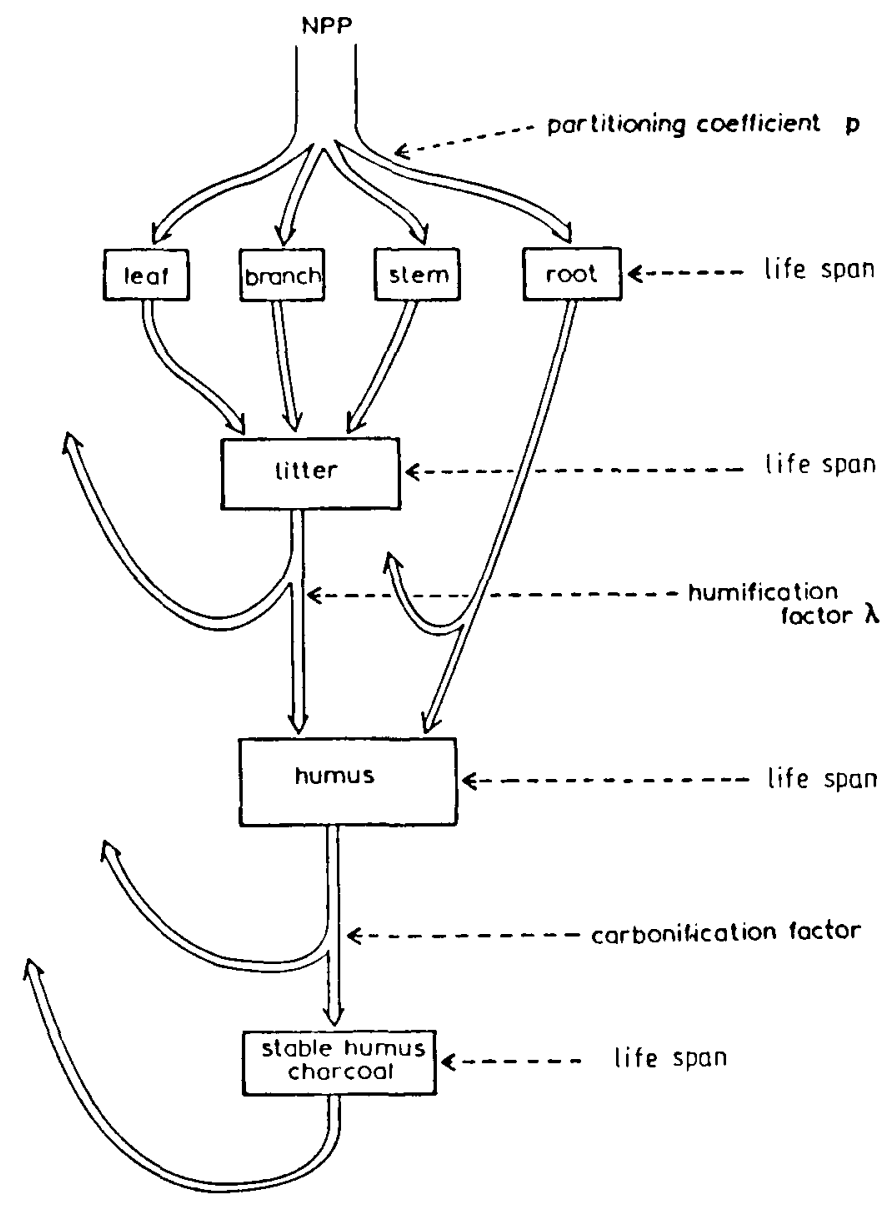

Fig. 4. General diagram of flow of carbon through an ecosystem.

rial burnt into the highly inert charcoal pool (Seiler \& Crutzen, 1980). Therefore in the long run repeated burning increases the carbon content of soils, at the expense of the atmospheric and oceanic reservoirs. Studies of the effect of deforestation tend to overestimate the immediately visible destruction, and to underestimate the less spectacular and slow process of regrowth. If the type of land use has not been changed, the area-based net primary productivity (NPP) is not affected and gives rise to regrowth of first pioneer vegetation, gradually changing to mature vegetation types. Except with low ground coverage by vegetation, NPP is hardly coupled to biomass.

On a global scale, NPP is stimulated by atmospheric $\mathrm{CO}_{2}$. Ranging from water limited to phosphorus limited, the relative stimulus varies between 0.7 and zero. Agriculture enhances soil weathering by digging and ploughing. Together with the 
tremendous growth of artificial fertilizer application, this results in a global increase of nutrient availability (eutrophication), which serves as another background stimulus of global NPP.

These factors together (charcoal formation, regrowth, and fertilization by $\mathrm{CO}_{2}$ and nutrients), are responsible for a compensation of the release rate of $\mathrm{CO}_{2}$ as caused by deforestation (Goudriaan \& Ketner, 1984). Indeed, at present the terrestrial biosphere is a net absorber of carbon at a rate of about $0-0.5 \mathrm{Gt} \mathrm{a}^{-1}$.

The terrestrial biosphere can be considered as a surface phenomenon with a negligible thickness. The thin biospheric crust of carbon-rich material on the earth's surface is spatially highly diversified. Different degrees of aggregation have been used to describe the complexity of the terrestrial biosphere. One of the most sophisticated systems is the databank compiled by Matthews (1983). Remote sensing data have contributed considerably to the mapping of the distribution of green leaf area on earth (Tucker et al., 1986).

Almost all biospheric carbon is concentrated on land, because of the relatively high longevity of wood and humus. In contrast, the lifetime of plankton is not measured in years but in days, and as a reservoir of carbon the plankton is negligible. Still the marine primary productivity is of utmost importance for the regulation of atmospheric $\mathrm{CO}_{2}$ by its effect on the carbon content of seawater.

Some $20 \%$ of the biotic carbon fixation in the upper ocean layer 'rains' down unobstructed by the thermal stratification. This precipitation rate is estimated at 8

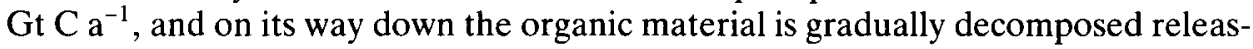
ing $\mathrm{CO}_{2}$ into the deep sea. Only a tiny fraction ultimately reaches the ocean floor. This downward pumping of organic material maintains the carbon content of the deep sea water at a much higher level, than it would have been otherwise. Its potential effect on atmospheric $\mathrm{CO}_{2}$ is depicted in Fig. 5, which shows a simulation result of a fictive change in the rate of precipitation of organic matter into the deep sea. The model used was the one described by Goudriaan \& Ketner (1984). A cessation

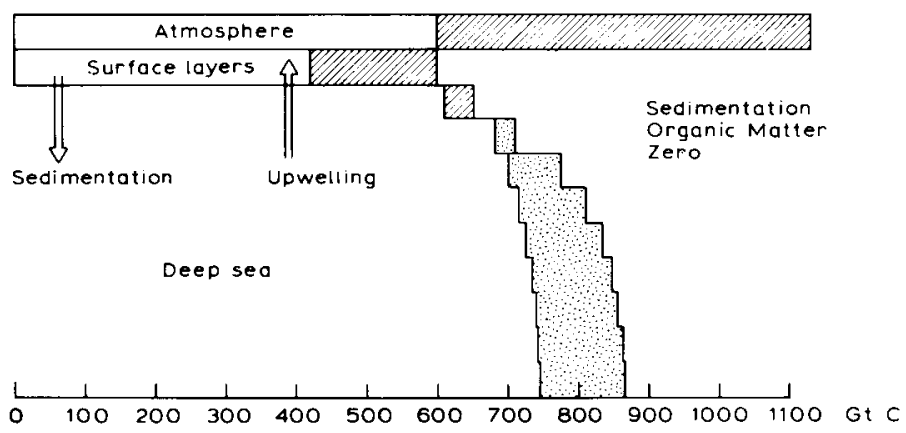

Fig. 5. Distribution of carbon over atmosphere and oceanic depth in two different model simulations. In the first simulation the distribution was in equilibrium with the present downward precipitation of organic matter from the ocean surface towards the deep sea. In the second simulation the precipitation was brought to zero. As a result after two hundred years the deep sea had lost carbon (stippled), whereas the upper layers and the atmosphere had gained carbon (hatched). 


\section{J. GOUDRIAAN}

of plankton growth would cause a $50 \%$ increase of atmospheric $\mathrm{CO}_{2}$ in about 200 years time, and a doubling of plankton growth would let it drop to far below 200 $\mathrm{cm}^{3} / \mathrm{m}^{3}$. Whatever mechanism stimulated the plankton growth, it is likely that such a change has been responsible for the fast changes of atmospheric $\mathrm{CO}_{2}$ in the Pleistocene.

The biospheric pumps of carbon are intimately connected with nutrient cycles of other elements. Plankton growth is strongly affected by supply rates of phosphorus and nitrogen, welling up from the deep sea (Raymont, 1980). Therefore the atmospheric $\mathrm{CO}_{2}$ changes were probably caused by changes in circulation patterns (Sarmiento \& Toggweiler, 1984; Siegenthaler \& Wenk, 1984) in the oceans, which in turn may have been changed by $\mathrm{CO}_{2}$ itself (Manabe \& Bryan, 1985). Once triggered, a single mechanism could not have completed the job, and powerful feedback loops must have amplified the responses.

Man-made changes of the biosphere are inevitable, and whether or not these changes will be amplified, time will surely tell. Human society can better be prepared for the outcome as regarded likely by scientists, but not be taken by surprise if things turn out differently. The global $\mathrm{CO}_{2}$ experiment that we are all in together is not over yet.

\section{References}

Anonymous, 1985. Carbon dioxide. Plant, Cell and Environment 8(6) 371-374

Bolin, B., E. T. Degens, S. Kempe \& P. Ketner (Eds.), 1979. The global carbon cycle. SCOPE 13. John Wiley \& Sons, Chichester, 491 pp.

Chamberlain, J. W., H. M. Foley, G. J. McDonald \& M. A. Ruderman, 1982. Climate effects of minor atmospheric constituents. In: W. C. Clark (Ed.), Carbon dioxide review: 1982, p. 253-277. Oxford University Press, Oxford.

Dickinson, R. E., 1982. Modeling climate changes due to carbon dioxide increases. In: W. C. Clark (Ed.), Carbon dioxide review: 1982, p. 101-133. Oxford University Press, Oxford.

Enoch, H. Z. \& B. A. Kimball, 1986. Carbon dioxide enrichment of greenhouse crops. CRC Press, Boca Raton, FL, USA, 432 pp.

Gammon, R. H., E. T. Sundquist \& P. J. Fraser, 1985. History of carbon dioxide in the atmosphere. In: J. R. Trabalka (Ed.), Atmospheric carbon dioxide and the global carbon cycle, DOE/ER-0239, U.S. Department of Energy, Washington, D.C.

Gezondheidsraad, 1983. Deeladvies inzake $\mathrm{CO}_{2}$-problematiek. Staatsuitgeverij, Den Haag, Netherlands, 199 pp.

Gezondheidsraad, 1986. $\mathrm{CO}_{2}$-problematiek, tweede deeladvies. Staatsuitgeverij, Den Haag, Netherlands, $150 \mathrm{pp}$.

Gifford, R. M., 1979. Growth and yield of $\mathrm{CO}_{2}$-enriched wheat under water-limited conditions. Australian Journal of Plant Physiology 6: 367-378.

Gifford, R. M., 1982. Global photosynthesis in relation to our food and energy needs. In: Govindjee (Ed.), Photosynthesis, Vol. II, p. 459-495. Academic Press, London.

Goudriaan, J. \& H. E. de Ruiter, 1983. Plant growth in response to $\mathrm{CO}_{2}$ enrichment, at two levels of nitrogen and phosphorus supply. 1. Dry matter, leaf area and development. Netherlands Journal of Agricultural Science 31: 157-169.

Goudriaan, J. \& P. Ketner, 1984. A simulation study for the global carbon cycle, including man's impact in the biosphere. Climatic Change 6: 167-192.

Harris, J. M. \& B. A. Bodhaine (Eds.), 1983. Geophysical monitoring for climatic change, No 11; Sum- 
mary report 1982. Environmental Research Laboratories/NOAA, U.S. Department of Commerce, Washington, DC.

Keeling, C. D., R. B. Bacastow \& T. P. Whorf, 1982. Measurements of the concentration of carbon dioxide at Mauna Loa Observatory, Hawaii. In: W. C. Clark (Ed.), Carbon dioxide review: 1982, p. 377-384. Oxford University Press, Oxford.

Kortleven, J., 1963. Kwantitatieve aspecten van humusopbouw en humusafbraak. Verslagen Landbouwkundige Onderzoekingen 69-1. Pudoc, Wageningen, Netherlands, $109 \mathrm{pp}$.

Lemon, E. R., 1984. $\mathrm{CO}_{2}$ and plants. Westview Press, Colorado, USA, 280 pp.

Lovelock, J. E., 1979. Gaia: a new look at life on earth. Oxford University Press, Oxford, United Kingdom.

Lucretius, 60 BC. De rerum natura. Translated into Dutch: Over de natuur. Polak \& Van Gennep, Amsterdam, Netherlands, $1984 ; 257 \mathrm{pp}$.

Manabe, S. \& K. Bryan, 1985. $\mathrm{CO}_{2}$-induced change in a coupled ocean-atmosphere model and its palaeoclimate implications. Journal of Geophysical Research 90 (C6): 11689-11707.

Matthews, E., 1983. Global vegetation and land use: new high-resolution data bases for climate studies. Journal of Climate and Applied Meteorology 22: 474-487.

Mook, W. G., 1986. ${ }^{13} \mathrm{C}$ in atmospheric $\mathrm{CO}_{2}$. Netherlands Journal of Sea Research 20: 211-223.

Nambudiri, E. M. V., W. D. Tidwell, B. N. Smith \& N. P. Hebbert, 1978. A $C_{4}$-plant from the Pliocene. Nature 276: 816-817.

Neftel, A., H. Oeschger, J. Schwander, B. Stauffer \& R. Zumbrunn, 1982. Ice core measurements give atmospheric $\mathrm{CO}_{2}$ content during the past 40,000 years. Nature 295: 220-223.

Neftel, A., E. Moor, H. Oeschger \& B. Stauffer, 1985. Evidence from polar ice cores for the increase in atmospheric $\mathrm{CO}_{2}$ in the last two centuries. Nature 315: 45-47.

Olson, J. S., R. M. Garrels, R. A. Berner, Th. V. Armentano, M. I. Dyer, \& D. H. Yaalon, 1985. The natural carbon cycle. In: J. R. Trabalka (Ed.), Atmospheric carbon dioxide and the global carbon cycle, p. 175-214. DOE/ER-0239, U.S. Department of Energy, Washington, D.C.

Raymont, J. E. G., 1980. Plankton and productivity in the oceans, 2nd ed., Vol. 1, Phytoplankton. Pergamon Press, Oxford, $489 \mathrm{pp}$.

Revelle, R. \& G. Kohlmaier, 1986. Increasing amplitudes of the seasonal $\mathrm{CO}_{2}$ cycle. In: C. Rosenzweig \& R. Dickinson (Eds.), Climate-vegetation interactions, p. 174-177. NASA Conference Publication 2440. Goddard Space Flight Center, Greenbelt, MD.

Sande Bakhuyzen, H. L. van de, 1937. Wetten bij den groei van tarwe en andere landbouwgewassen. Landbouwkundig Tijdschrift 49: 885-900.

Sarmiento, J. L. \& J. R. Toggweiler, 1984. A new model for the role of the oceans in determining atmospheric $\mathrm{P}_{\mathrm{CO}_{2}}$. Nature 308: 621-624.

Schlesinger, M. E. \& J. F. B. Mitchell, 1985. Model projections of the equilibrium climatic response to increased carbon dioxide. In: M. C. McCracken \& F. M. Luther (Eds.), The potential climatic effects of increasing carbon dioxide, p. 81-148. DOE/ER-0237, U.S. Department of Energy, Washington, D.C.

Seiler, W. \& P. J. Crutzen, 1980. Estimates of gross and net fluxes of carbon between the biosphere and the atmosphere from biomass burning. Climatic Change 2: 207-247.

Siegenthaler, U. \& Th. Wenk, 1984. Rapid atmospheric $\mathrm{CO}_{2}$ variations and ocean circulation. Nature 308: 624-626.

Strain, B. R. \& J. D. Cure (Eds.), 1985. Direct effects of increasing carbon dioxide on vegetation. DOE/ER-0238, U.S. Department of Energy, Washington, USA, $286 \mathrm{pp}$.

Trabalka, J. R. (Ed.), 1985. Atmospheric carbon dioxide and the global carbon cycle. DOE/ER-0239, U.S. Department of Energy, Washington, USA, $315 \mathrm{pp}$.

Tucker, C. J., I. Y. Fung, C. D. Keeling \& R. H. Gammon, 1986. Relationship between atmospheric $\mathrm{CO}_{2}$ variations and a satellite-derived vegetation index. Nature 319: 195-199.

Washington, W. M. \& C. L. Parkinson, 1986. An introduction to three-dimensional climate modeling. Oxford University Press, Oxford, $422 \mathrm{pp}$. 